nach BergmeYer (4) zeigt eine Fehlerbreite von $\pm 2 \%$. Die Ergebnisse resultieren aus einer Ablesung während der Katalasereaktion. Ablesungsfehler lassen sich korrigieren, wenn man mehrere Messungen in einem kurzen Reaktionsabschnitt vornimmt und zu einem Durch- schnittswert zusammenfaßt (10). - Die Vorteile der hier beschriebenen Methode zur Katalaseaktivitätsbestimmung für klinische Zwecke bestehen im Vergleich zu älteren Methoden in ihrer schnelleren Durchführung und größeren Genauigkeit.

\title{
Literatur
}

1. HelleR, H., Röntgen-Laborat. praxis, Stuttgart 10, 183 (1957). - 2. Lück, H., Biochem. Z. 328, 411 (1957). - 3. ScHürz, E., Übet die Katalaseaktivität des Säuglingsblutes und ihre Bestimmung mittels Polarographie, Med. Diss., Würzburg (1954). 4. BergmeYer, H. U., Biochem. Z. 327, 255 (1955). - 5. Herbert, D., Methods in Enzymology Vol. II, 764, 780 (1955). - 6. SENTER, G., Z. physik. Chem. 44, 257, (1903). - 7. v. EuLER, H. und K. Josephson, Liebigs Ann. Chem. 452, 158 (1927); 455, 1 (1927). -8. Zerle, K., Katalase, S. 2615 aus Bamann, E. und K. Myrbäck, Die Methoden der Fermentforschung III, Georg Thieme, Leipzig (1941). - 9. v. Euler, H. und K. ZmILE, Die Katalasen, aus v. Euler, H., Chemie der Enzyme II, 3. Bergmann, München S. 663 (1934). - 10. Herder, H., Die Blutkatalaseaktivität im
Kindesalter und ihre Beeinflussung durch bestimmte Erkrankungen und Vitamin K-Präparate, Med. Diss., Berlin (1962). - 11. Hoffmann-Ostenhof, O., Fortschr. Chem. org. Naturstoffe (Wien) 6, 154 (1950). - 12. SErde, G., Biochem. Z. 308, 175 (1941). -13. Brschoff, H., Arch. Kinderhk., Stuttgart 82, 189 (1927). 14. BeERS, R. F. und J. W. Sizer, J. biol. Chemistry 195, 133 (1952). - 15. Kurokawa, H., Tohoku J. Exper. Med. 14, 520, 539 (1929/30). - 16. v. ThIemen, G. J., Dtsch. Arch. klin. Med. 131, 113 (1920). - 17. Jones, P. E. H. und R. A. MCCANCE, Biochem. J. 45, 464 (1949). - 18. Morgulis, S. und M. Beber, J. biol. Chemistry 72, 91 (1926). - 19. TheoreLl, H., Experientia, Basel 4, 100 (1948).
Priv.-Doz. Dr. med. Egon Werner Kinderklinik der Freien Universität Berlin (Kaiserin Auguste Victoria Haus) 1 Berlin 19, Heubnerweg 6

\section{Isolierung und Feststellung der chemischen Zusammensetzung eines Perchlor- säure-löslichen Glykoproteids aus dem Urin von Plasmocytom-Kranken*)}

\author{
Von \\ H. WeICKer, K. HuhNSTOCK und D. GRÄSSLIN \\ Aus der Medizinischen Universitäts-Poliklinik Heidelberg (Direktor: Professor Dr. H. Plügge) \\ Meinem verehrten Lehrer, Herrn Professor S. J. Thannhauser, zum Gedächtnis
}

(Der Schriftleitung zugegangen am 6. März 1963)

\begin{abstract}
Aus dem Gesamturoprotein-Komplex von Plasmocytom-Patienten wurde durch Hydrolyse und nachfolgende Lipid-Extraktion der gefriertrocknen Substanz ein Glykopeptid isoliert, das ein Molekulargewicht von 19900 besitzt. In Ultrazentrifuge und Elektrophorese ist es homogen. Es ist in Wasser hitzestabil, in $0,6 \mathrm{~m}$ Perchlorsäure gut löslich, in 10 proz. Trichloressigșäure hịngegen unlöslich. Es enthält 16 verschiedene Aminosäuren und ist methioninfrei. Der Gesamtkohlenhydratgehalt beträgt 38,1\%. Die Kohlenhydrate haben folgende molare Verteilung: Ga:Ma:Glu:Fu:Rh:GlA:GaA:NS = 10:5:5:4:2:8:2:5. Es unterscheidet sich physiko-chemisch von anderen Perchlorsäure-löslichen Proteiden des Serums und Urins. Es dürfte für die Uroproteine des Plasmocytoms charakteristisch sein, da es im Harn von Normalpersonen und bei Proteinurien anderer Genese nicht isoliert werden konnte.
\end{abstract}

A glycopeptide, molecular weight 19.900, was isolated from the total uroprotein complex of plasmacytoma patients by lipid extraction of the freeze-dried product after hydrolysis. It is homogeneous in the ultracentrifuge and in electrophoresis. It is thermostable in water, very soluble in $0.6 \mathrm{M}$ perchloric acid and insoluble in $10 \% \mathrm{TCA}$. It contains 16 different amino acids and no methionine. The total carbohydrate is $38.1 \%$ and of the following molar composition: $\mathrm{Ga}: \mathrm{Ma}: \mathrm{Glu}: \mathrm{Fu}: \mathrm{Rh}: \mathrm{GlA}: \mathrm{GaA}: \mathrm{NA}=10: 5: 5: 4: 2: 8: 2: 5$. Physicochemically, it is different from other perchloric acid-soluble proteins of serum and urine. It could not be found in normal urine or that from other types of proteinuria; it may thus be a characteristic uroprotein of plasmacytoma.

*) Mit Unterstützung der Deutschen Forschungsgemeinschaft. 
Bei Plasmocytomen und Makroglobulinämie Waldenström konnten die Gesamt-Uroproteine durch Hydrolyse mit Wasser bei $65^{\circ}$ und $70^{\circ}$ und anschließender Lipidextraktion in mehrere Uroprotein-Fraktionen aufgetrennt werden, die sich in ihrem Molekulargewicht, Polypeptid- und Kohlenhydratgehalt, in ihrer elektrophoretischen Wanderungsgeschwindigkeit und ihrem immunoelektrophoretischen Verhalten unterscheiden (1, $2,3,4)$. Aus dem Proteid nach Lipidextraktion konnte ein relativ niedermolekulares Glykoproteid mit einem Molekulargewicht von $19900^{1}$ ) isoliert werden. Es erwies sich in Elektrophorese und Ultrazentrifuge als einheitliche Substanz. Nach seiner Aminosäure- und KohlenhydratZusammensetzung und seinen physiko-chemischen Eigenschaften unterscheidet es sich von anderen Glykoproteiden und Mucoiden des Serums und des Urins. Es ist zu erwarten, daß dieses kohlenhydratreiche, niedermolekulare Glykoproteid für die Uroprotein-Ausscheidung bei Paraproteinosen charakteristisch ist, da es bei Normalpersonen und bei Patienten mit Proteinurien anderer Genese nicht gefunden wurde. Die besondere Eigenschaft dieses Glykoproteids und seine Sonderstellung unter den Mucoiden und Glykoproteiden gab Veranlassung zu umfangreichen biochemischen Untersuchungen, über die hier berichtet werden soll.

\section{Methodik}

Zur Isolierang von $500 \mathrm{mg}$ reinem Glykoproteid wurden insgesamt $10 l$ Urin von einer Patientin mit Plasmocytom nach folgender Methode aufgearbeitet:

1. Zéntrifugation und Entfärben des Urins mit Tierkohle, Zugabe von 1:50 000 Merthiolat, 24 Stdn. erschöpfende Dialyse des filtrierten Urins gegen fließendes Wasser und anschließend gegen Aqua dest.

2. Abtrennung des proteinreichen und kohlenhydratarmen Bence Jones'schen Eiweißkörpers (,BJE I“) durch Erhitzen auf $55^{\circ}$ bis $65^{\circ}$ bei $\mathrm{pH}=6,5$. Sofortiges Zentrifugieren und anschließende Filtration des Urins.

3. Erhitzen des Filtrates auf $70^{\circ}$ bei $\mathrm{pH}=8,10 \mathrm{Min}$. Abzentrifugation eines koagulierten Uroproteines („BJE II"), das kohlenhydratreicher ist als BJE I.

4. Filtration des Uberstandes und Zentrifugation bei $17000 \mathrm{U} /$ Min. Gefriertrocknung des wasserklaren UUberstandes und anschließende Trocknung über Phosphorpentoxyd bis zur Gewichtskonstanz. Extraktion dieses kohlenhydratreichen, lipidhaltigen, proteinarmen Uroprotein-Komplexes („PRU II") $12 \mathrm{Stdn}$. mit absolutem Methanol und 12 Stdn. mit Chloroform-Methanol (2:1) im Soxhlet-Verfahren.

5. Aufschlämmung des trockenen, lipidfreien Extraktionsrückstandes in Aqua dest., mehrfaches Waschen mit Aqua dest. und Zentrifugation. Der klare, filtrierte Uberstand enthält das niedermolekulare Glykoproteid in Lösung. Dialyse der wäßr. Glykopeptid-Lösung gegen Aqua dest., Gefriertrocknung und anschließende Trocknung über Phosphorpentoxyd. Erhitzen der 1proz. wäßr. Glykoproteid-Lösung, die aus der Trockensubstanz angesetzt wurde. Erhitzungsdauer $5 \mathrm{Min}$.; $\mathrm{pH}=5 ; 100^{\circ}$. Anschließend Zentrifugation bei 17000 U/Min. Emeute Dialyse des Úberstandes, Gefriertrocknung und Trocknung über Phosphorpentoxyd bis zur Gewichtskonstanz.

1) Mol.-Gew. korrigiert nach Asche-Bestimmung.

\section{Folgende Untersuchungen wurden durch- geführt}

\section{Elektrophorese}

a) Papierelektrophorese mit horizontaler Trenntechnik in verschiedenen Puffersystemen: Veronal-Natrium $\mathrm{pH}=8,6$; Pyridin: Essigsäure:Wasser $=100: 10: 890, \mathrm{pH}=6,4 ;$ Pyridin:Eisessig: Wasser $=30: 50: 900, \mathrm{pH}=4,6 ;$ Pyridin:Essigsäure: Wasser $=$ $10: 100: 890, \mathrm{pH}=3,6 ;$ Ameisensäure:Pyridin:Wasser $=160: 88$ : 752, $\mathrm{pH}=3,3$ (5). Auftragsmenge pro Papierstreifen $1 \mathrm{mg}$, Laufzeit 4-6 Stdn., 220 V, $10 \mathrm{~mA}$ pro Papierstreifen. Zur Ermittlung des isoelektrischen Punktes wurde nach Festlegung des groben $\mathrm{pH}$-Bereiches zwischen 4,6 und 3,3 das $\mathrm{pH}$ stufenweise reduziert. Die Anfärbung erfolgte für die Proteine mit Amidoschwarz $10 \mathrm{~B}$, die freien Aminogruppen wurden mit einem 2proz. NinhydrinButanol-Spray dargestellt. Der Nachweis reduzierender OHGruppen wurde mit Anilinphthalat, p-Anisidinphthalat und alkalischer Silbernitratlösung vorgenommen. Außerdem wurden die Zucker und Aminozucker noch mit Perjodat-Benzidin identifiziert. Die Glykoproteid-Färbung wurde mit der PAS-Reaktion durchgeführt.

b) Agarelektrophorese mit der LKB-Apparatur: 1proz. Lösung von Agar (Dif 'o „Noble“); Natrium-Veronalpuffer $\mathrm{pH}=8,6$; Auftragsmenge $14 \mathrm{ml}$ pro Rahmensektion; Auftragsmenge der Substanz 0,008 mg; Trennzeit $90 \mathrm{Min}$., $250 \mathrm{~V} 8 \mathrm{~mA}$ Rahmensektion. Vergleich mit gepooltem Kontrollserum von 20 gesunden Blutspendern. Amidoschwarz- und PAS-Färbung.

c) Stärke-Elektrophorese nach SMITHIES, modifiziert nach KUNKEL: Doppel-Puffer A) Tris-Citronensäure, $\mathrm{pH}=8,9$ nach Poulik; B) Borsäure- $\mathrm{NaOH}, \mathrm{pH}=8,5,15 \mathrm{proz}$. Stärke-Gel (Serva-Entwicklungslabor Heidelberg). Trennung Puffer A: $550 \mathrm{~V}, 3$ Stdn. Puffer B: $600-550$ V, 3 Stdn.; Kammertemperatur - $3^{\circ}$. Färbung mit Amidoschwarz und Supracenviolet $3 \mathrm{~B}$, Trichloressigsäure. Letztere erlaubt die photometrische Registrierung mit dem Extinktionsschreiber ( $\mathrm{Fa}$. Zeiss) analog zu den PapierelektrophoreseDiagrammen (6).

2. Immunologische Untersuchungen mit der ImmunicElektrophorese nach ScheIdegger (7) und Technik nach OsserMANN (8). Zweidimensionale Diffusion im Agar-Gel nach OuchterLONY (9).

3. Die Ultrazentrifugen-Untersuchungen wurden mit dem Modell Spinco E vorgenommen (Rotor AN-D, Standardzelle $12 \mathrm{~mm} 4^{\circ}$ und Uberschichtungszelle SBCT, Temperatur $20^{\circ}$ und $25^{\circ}$; Philpot-Svensson-Optik; keine Korrektur des JohnstonOgston-Effektes).

4. Die Molekulargewichts-Bestimmung konnte mit der Ultrazentrifuge nach Kombination von Sedimentations- und Diffusionsläufen quantitativ durchgeführt werden (10). Die orientierende Molekulargewichtsbestimmung wurde in Diffusionszellen nach der Methode von NorTHRUP und ANSON (11) vorgenommen. Als Vergleichsprotein wurde Albumin in Lösung mit gleicher Konzentration verwendet.

5. Hydrolyse-Verfahren. Die chromatographische und chemische Bestimmung der einzelnen Konstituenten machte beim Vorliegen von Hexosen, Methylpentosen, Aminozuckern, Neuraminsäure und Aminosäuren die Anwendung zahlreicher sowohl robuster als auch schonender Methoden zur Hydrolyse erforderlich.

a) Aminosäuren: Zur papierchromatographischen Darstellung der Aminosäuren wurde mit $4 n \mathrm{HCl} 4 \mathrm{Stdn} .100^{\circ}$ unter Luftabschluß hydrolysiert. Die Salzsäure wurde in der Wärme im Stickstoffstrom abgedampft. Zur quantitativen Bestimmung der Aminosäuren wurde $24 \mathrm{Stdn}$. in $6 n \mathrm{HCl}$ unter Stickstoff-Atmosphäre bei $105^{\circ}$ in zugeschmolzenen Röhrchen hydrolysiert.

b) Koblenbydrate: Zur Darstellung der Kohlenhydrat-Komponenten wurde das niedermolekulare Glykoproteid sowohl mit 80proz. Ameisensäure 2 und $4 \mathrm{Stdn}$. bei $100^{\circ}$, mit 50proz. Trichloressigsäure $4 \mathrm{Stdn}$. bei $100^{\circ}$, mit $4 n \mathrm{HCl} 4 \mathrm{Stdn}$. bei $100^{\circ}$ und mit $4 n \mathrm{H}_{2} \mathrm{SO}_{4} 4 \mathrm{Stdn}$. bei $100^{\circ}$ hydrolysiert. Die Salzsäure, die Ameisensäure und die Trichloressigsäure wurde durch Abdampfen 
im Stickstoffstrom bei $70^{\circ}$ entfernt. Schwefelsäure wurde durch Bariumhydroxyd in der Hitze als Bariumsulfat gefällt. Nach Entfernung der Säuren wurden Lösungen des hydrolysierten Glykoproteids zur chemischen und chromatographischen Untersuchung hergestellt. Neben diesen Säurehydrolysen wurden Kombinationshydrolysen mit 80proz. Ameisensäure $2 \mathrm{Stdn}$. und - nach Entfernung der Ameisensäure - eine 2-stdg. Hydrolyse mit $4 n \mathrm{HCl}$ vorgenommen. Außerdem wurde nach 2-stdg. Hydrolyse mit 80proz. Ameisensäure nach Entfernung dieser Säure 2 Stdn. mit 50proz. Trichloressigsäure bei $100^{\circ} 2 \mathrm{Stdn}$. hydrolysiert.

c) Partielle Hj'drolyse: Zur partiellen Abtrennung der Kohlenhydratkomponenten und zur Ermittlung der Stabilität der Kohlenhydratbindung wurde mit Ionenaustauscher Amberlite IR 120, 50-100 Mesh in H-Form bei verschiedenem $\mathrm{pH}$ und verschiedenen Temperaturen hydrolysiert; im Anschluß daran wurde gegen Aqua dest. dialysiert. $60 \mathrm{mg}$ Substanz wurden in kleinstmöglicher Menge Wasser gelöst und mit der dreifachen Menge analysenfertigen Ionenaustauschers im Hydrolyscröhrchen gut vermischt. Nach 3 Stdn. bei $20^{\circ}$ wurde das Substanz-IonenaustauscherGcmiscb in einen Dialyseschlauch gebracht und 2 Tage gegen Aqua dest. ausreichend dialysiert. Die Gesamtkohlenhydrate wurden im Dialysat und Dialyserückstand chemisch und chromatographisch untersucht. Mit dem gleichen Versuchsansatz wurde dann bei $\mathrm{pH}=5,100^{\circ} 3 \mathrm{Stdn}$. und anschließend bei $\mathrm{pH}=1$, $3 \mathrm{Stdn}$. und $100^{\circ}$ hydrolysiert und danach dialysiert. $\mathrm{Da}$ bei allen Stufen der Ionenaustauscher-Hydrolyse im Dialysat, Dialyserückstand und nach Elution des Ionenaustauschers mit $\mathrm{H}_{2} \mathrm{O}$ keine Hexosamine nachweisbar waren, wurden die Hexosamine mit $0,2 n \mathrm{HCl}$ im Anschluß an die Hydrolyse bei $\mathrm{pH}=1,3 \mathrm{Stdn}$. $100^{\circ}$ eluiert. Dic Dialysate und Eluate wurden im Rotationsverdampfer bei $40^{\circ}$ zur Trocknung gebracht und $1 \mathrm{~g}$-proz. Lösungen davon angesetzt.

6. Chemische Untersuchungen. Die chemischen Untersuchungen des Glykoproteids wurden in der eingewogenen Trockensubstanz und in aliquoten Teilen des mit Säure- oder Ionenaustauscher hydrolysierten Glykoproteids ausgeführt.

a) Quantitative Aminosäuren-Bestimmungen wurden nach Hydrolyse mit dem Amino-Acid-Analyser Modell 120 nach der Methode von SteIN und MOore (12) vorgenommen.

b) Die Hexosen wurden mit der Anthron- und Orcin-Methode bestimmt. Die Extinktionswerte wurden auf einen Glukose-, Galaktose-, Mannose-Standardwert bezogen.

c) Die Metbj/pentosen wurden nach Dische und Shetrues (13) mit der Cystein-Hydrochlorid-Methode bestimmt.

d) Die Nestraminsäure wurde nach Svennermolm (14) mit der Resorcin-Methode ermittelt. Hierbei konnten wir entsprechend der Originalvorschrift durch $15 \mathrm{Min}$. Erhitzen auf $100^{\circ} \mathrm{mit}$ Resorcin-Salzsäure die Neuraminsäure nicht vollständig aus dem eingewogenen Glykopolypeptid abspalten. Es wurde deshalb die Resorcin-Methode nach vorausgegangener Hydrolyse mit 40proz. Ameisensäure $30 \mathrm{Min}$. und nach Ionenaustauscher-Hydrolyse durchgeführt. Außerdem wurde die Neuraminsäure-Bestimmung mit Variation der Erhitzungszeit der Resorcin-Methode vorgenommen $(15,30,60$ und $120 \mathrm{Min}$.).

e) Die Hexosamin-Bestimmung wurde nach Elson-Morgan (15) ausgeführt.

f) Der Gesamtstickstoff wurde näch KJELDaHL und nach Dumas ermittelt. Hieraus wurde nach Abzug des Stickstoffes der Aminozucker der Polypeptidgehalt errechnet.

g) Die Polypeptid-Bestimmung wurde mit der Biuret-Methode vorgenommen.

h) Die Elementar-Analyse wurde in üblicher Weise durchgeführt.

\section{Chromatographie}

a) Aminosäuren und Aminozucker: Die Aminosäuren und Aminozucker wurden nach Durchführung der oben beschriebenen Hydrolysen mit $4 n \mathrm{HCl}$ eindimensional auf Whatman-Papier Nr. I, absteigend in Lösungsmitteln Butanol:Pyridin:Wasser $=1: 3: 5$ getrennt. Nach 18 Stdn. wurde das Chromatogramm getrocknet und erneut in demselben Lösungsmittel $12 \mathrm{Stdn}$. chromato- graphiert. Die zweidimensionale Trennung erfolgte aufsteigend mit den Lösungsmitteln: 1. Pbase - Butanol:Eisessig:Wasser = 480:120:200; 12 Stdn. 2. Pbase - 90\% Phenol + 1\% Ammoniak; 8 Stdn. (5).

Die Chromatogramme wurden mit 2proz. Ninhydrin-ButanolSpray bei $110^{\circ}$ inncrhalb von $10 \mathrm{Min}$. entwickelt. Die Auftragsmenge zur Aminosäuren- und Aminozucker-Trennung betrug 50-80 $\mu \mathrm{g}$ hydrolysiertes Glykoproteid.

b) Gesamtkoblenbydrate: Hexosen, Methylpentosen, Aminozucker und Neuraminsäure wurden nach Hydrolyse ebenfalls auf Whatman-Papier I mit der gleichen Technik absteigend chromatographiert. Die Auftragsmenge betrug 150-180 $\mu$ g Glykoproteid. Außerdem wurde die Dünnschichtchromatographic auf MNCellulose $30 \mathrm{G}$ unter Verwendung des gleichen Lösungsmittels ausgeführt. Die Trennzeit betrug hierbei $2-3$ Stdn.; Auftragsmenge 5-10 $\mu \mathrm{g}$ Substanz. Zum Nachweis der Zucker und Aminozucker wurde Anilinphthalat oder p-Anisidinphthalat für Papicrund Dünnschichtchromatogramme als Spray verwandt (16). Außerdem wurden auf Papier die reduzierenden OH-Gruppen mit alk. Silbernitrat sichtbar gemacht. Zur Identifizierung der Neuraminsäure wurde noch zusätzlich Perjodat-Benzidin-Spray (5) benutzt. Die quantitative papierchromatographische Trennung der Hexosen, Methylpentosen und Aminozucker wurde nach Auftrag von $25 \mathrm{mg}$ hydrolysierter Substanz nach IonenaustauscherHydrolyse vorgenommen. Hierbei wurde das im Vakuum-Verdampfer eingeengte Dialysat über $25 \mathrm{~cm}$ Papierbreite punktförmig aufgetragen und in der üblichen Weise chromatographiert. Nach Identifizierung der Zucker in den abgetrennten Randpartien mit Anilinphthalat wurden die Papierzonen der einzelnen Zucker herausgeschnitten und mit $\mathrm{H}_{2} \mathrm{O}$ eluiert. Durch Rechromatographie wurde die Reinheit der Zuckertrennung überprüft. Danach wurden die Hexosen mit der Anthron- und Orcin-Methode in den Eluaten bestimmt. Die Extinktionswerte wurden auf einen speziellen Zuckerstandard der jeweils in Frage kommenden Zuckerart bezogen. Die Methylpentosen wurden mit der Cystein-Hydrochloridmethode von Dische und Shettres ermittelt. Die eluierten Aminozucker wurden nach Elson-Morgan bestimmt. Außerdem wurden die getrennten Aminozucker noch mit Silbernitrat entwickelt und die Aminozucker-Banden photometrisch mit dem Extinktionsschreiber ( $\mathrm{Fa}$. Zeiss) als Diagramm dargestellt und planimetrisch ausgewertet (17). Die Aminozucker, die durch Ninhydrin-Reagenz zur Darstellung der freien Aminogruppe und mit Anilinphthalat und alkalischer Silbernitratlösung zum Nachweis reduzierender OH-Gruppen identifiziert worden waren, wurden spezifisch nach Ninhydrin-Abbau durch die dabei entstehenden nächstniederen Pentosen chromatographisch identifiziert (18). Der Ninhydrin-Abbau wurde mit einer 2proz. Ninhydrin-Konzentration in 4proz. Pyridin in zugeschmolzenen Kapillaren über $50 \mathrm{Min}$. bei $100^{\circ}$ ausgeführt. Die SubstanzEinwaage betrug $20 \mathrm{mg}$; Glukosamin wurde zu Arabinose und Galaktosamin zu Lyxose abgebaut.

\section{Infrarotspektren}

Die Infrarotspektren wurden mit dem Gerät nach Perkin-Elmer im Kaliumbromid-Preßling aufgenommen.

\section{Fermentativer Glukosenachweis}

Die Glukose wurde fermentativ nach Säurehydrolyse und Ionenaustauscher-Hydrolyse mit der Glukoxydase-Reaktion (19) und durch den Umsatz von TPN durch Hexokinase und Glukose-6Phosphat-Dehydrogenase zu TPN-H nachgewiesen (20).

\section{Ergebnisse}

Aus dem Urin von Plasmocytom-Kranken mit positiver Bence Jones'scher Eiweißkörper-Ausscheidung isolierten wir ein relativ niedermolekulares Glykoproteid. Die Konzentration im Urin beträgt $40-50 \mathrm{mg} \%$; es ist in Wasser hitzestabil und gut löslich. In 0,6 $\mathrm{m}$ Perchlorsäure ist es ebenfalls leicht löslich, jedoch nicht in 10proz. Trichloressigsäure. In der Ultrazentrifuge, bei 
der Papier- und Stärke-Gel-Elektrophorese ist es bei $\mathrm{pH}=7-8,5$ homogen (Abb. 1). In der Immunoelektrophorese zeigen sich zwei feine Präzipitationslinien, die ebenfalls im $\alpha_{1}$-Globulin-Bereich liegen und partielle Antigen-Gemeinschaft gegenüber Antihumanserum vom Kaninchen aufweisen (Abb. 2). Der iso-
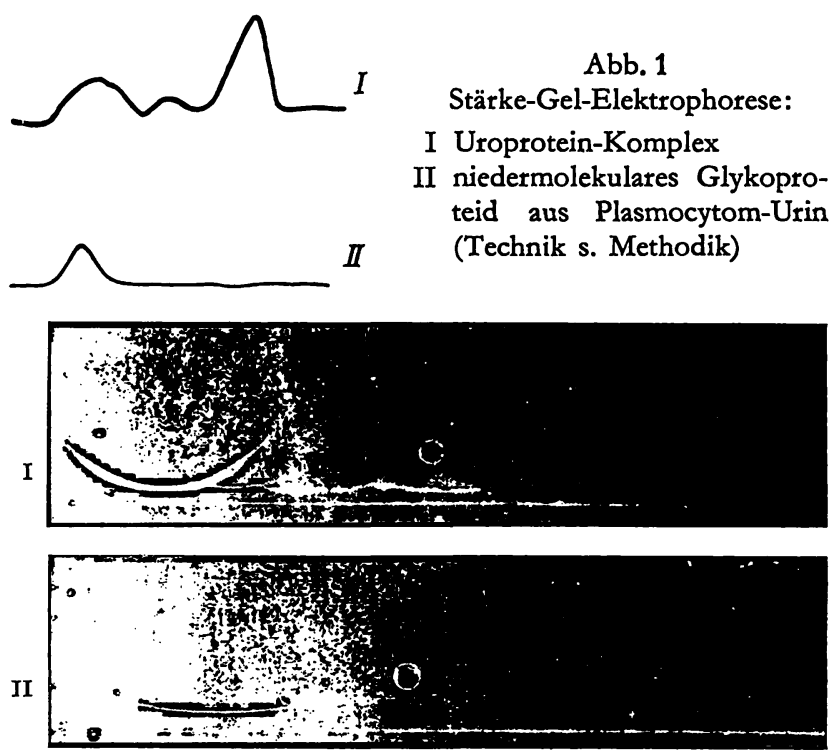

Abb. 2

Immunoelektrophorese: I Gesamturoprotein, II niedermolekulares Glykoproteid (Technik s. Methodik)

elektrische Punkt liegt zwischen 3,6 und 3,3. Das Molekulargewicht wurde mit der kombinierten Sedimentations- und Diffusionsmessung nach Svedberg in der Ultrazentrifuge bestimmt und betrug $19900 \pm 3 \%$. Die $S_{20}^{\circ}$-Konstante ist $1,43 \times 10^{-13}$. Die orientierende Molekulargewichtsbestimmung durch Diffusionsmessung nach NoRTHRUP und ANson ergab ein Molekulargewicht um 15000 (Tab. 1).

Tab. 1

Molekulargewichtsbestimmung des Glykoproteids nach SvedBerG und Northrup und Anson (Mol.-Gew. ohne Berücksichtigung des Asche-Gehaltes)

Molekulargewichtsbestimmung nach SVEDBERG:

Sed. Geschw.-Messungen

\begin{tabular}{cccc}
\hline $\begin{array}{c}\text { Konz. } \\
\%\end{array}$ & U/Min. & $\begin{array}{c}\text { Sed. Koeff. (in } \\
\text { SvEDBERG-Einheit) }\end{array}$ & $\begin{array}{c}\text { Sed. Konstanten (in } \\
\text { SvEDBERG-Einheit) }\end{array}$ \\
\hline 1,036 & 50740 & $1,48 \times 10^{-13}$ & \\
0,617 & 50740 & $1,42 \times 10^{-13}$ & $1,429 \times 10^{-13}$ \\
0,408 & 50740 & $1,47 \times 10^{-13}$ & \\
\hline
\end{tabular}

Diff. Geschw.-Messungen

\begin{tabular}{cccc}
\hline Konz. $\%$ & U/Min. & Diff. Koeff. & . Diff. Konstante \\
\hline 1,036 & 4609 & $5,49 \times 10^{-7}$ & \\
0,670 & 4609 & $5,87 \times 10^{-7}$ & $6,85 \times 10^{-7}$ \\
0,408 & 4609 & $6,42 \times 10^{-7}$ & \\
\hline
\end{tabular}

Molekulargewichtsbestimmung nach NORTHRUP und ANSON: Mol.-Gew. 15000

\section{Polypeptid-Anteil}

Der Gesamt-N-Gehalt des Glykoproteids, bestimmt nach KJELDAHL, betrug 8,9. Hieraus läßt sich unter Abzug des N-Gehaltes der Aminozucker der PeptidAnteil berechnen; er beträgt $57 \%$. Das entspricht dem Wert, der auch mit der Biuret-Methode ermittelt wurde. Nach Hydrolyse mit $4 n \mathrm{HCl} 4 \mathrm{Stdn} .100^{\circ}$ konnten im zweidimensionalen Chromatogramm 16 verschiedene Aminosäuren mit Ninhydrin identifiziert werden, wie aus Abbildung $3 \mathrm{zu}$ ersehen ist. Methionin war nicht nachweisbar. Bei der quantitativen Aminosäure-Bestimmung nach der Methode von STEIN und MOop̣e (12) wurden die 16. Aminosäuren erfaßt, deren prozentuale Verteilung im Vergleich zu den Werten des Bence Jones'schen Proteins und des GesamturoproteinKomplexes aus Abbildung $4 \mathrm{zu}$ ersehen ist. Im Gegensatz zu dem Gesamtkomplex und dem Bence Jones'schen Eiweißkörper war das Glykoproteid methioninfrei (21, 22). Im Vergleich mit dem Gesamturoprotein ist eine Zunahme von Prolin, Alanin, Valin und Tyrosin und eine Abnahme von Asparaginsäure, Arginin, Glycin, Leucin, Cystein und Phenylalanin festzustellen. In Gegenüberstellung zu dem BJE findet man eine $\mathrm{Zu}-$ nahme bei Prolin, Alanin, Cystein und eine Abnahme bei Arginin, Asparaginsäure,.Glycin, Leucin, Phenylalanin und Serin.

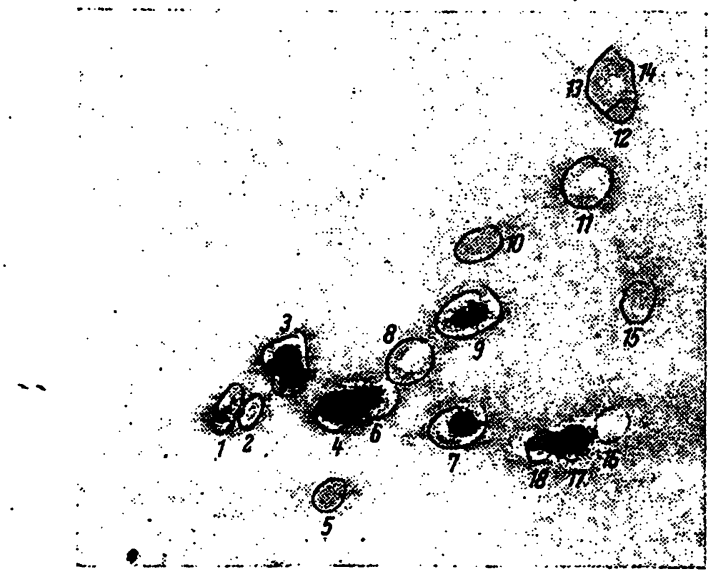

Abb. 3

Aminosäurechromatogramm des niedermolekularen Glykoproteids. Hydrolyse: $4 \mathrm{Stdn}$. $4 n \mathrm{HCl}$, Papier: Whatman I, Lösungsmittel A) Butanol:Eisessig: Wasser $=480: 120: 200,12$ Stdn.; B) 90proz. Phenol und 1proz. Ammoniak, 8 Stdn., Auftragsmenge $60 \mu \mathrm{g}$, Entwickler 2proz. Ninhydrin/Butanol als Sprühmittel;

$\begin{array}{lcl} & \text { Erhitzen } 10 \text { Min., } 110^{\circ} . \\ 1=\text { Cystein } & 7=\text { Glukosamin } & 13=\text { Leucin } \\ 2=\text { Asparaginsäure } & 8=\text { Threonin } & 14=\text { Isoleucin } \\ 3=\text { Glutaminsäure } & 9=\text { Alanin } & 15=\text { Prolin } \\ 4=\text { Serin } & 10=\text { Tyrosin } & 16=\text { Arginin } \\ 5=\text { Galaktosamin } & 11=\text { Valin } & 17=\text { Lysin } \\ 6=\text { Glycin } & 12=\text { Phenylalanin } & 18=\text { Histidin }\end{array}$

Gesamtkohlenhydrate

Die Gesamtkohlenhydrate wurden sowohl direkt mit den Zuckerreagenzien als auch nach Hydrolyse der Substanz mit verschiedenen Säuren oder Ionenaus- 


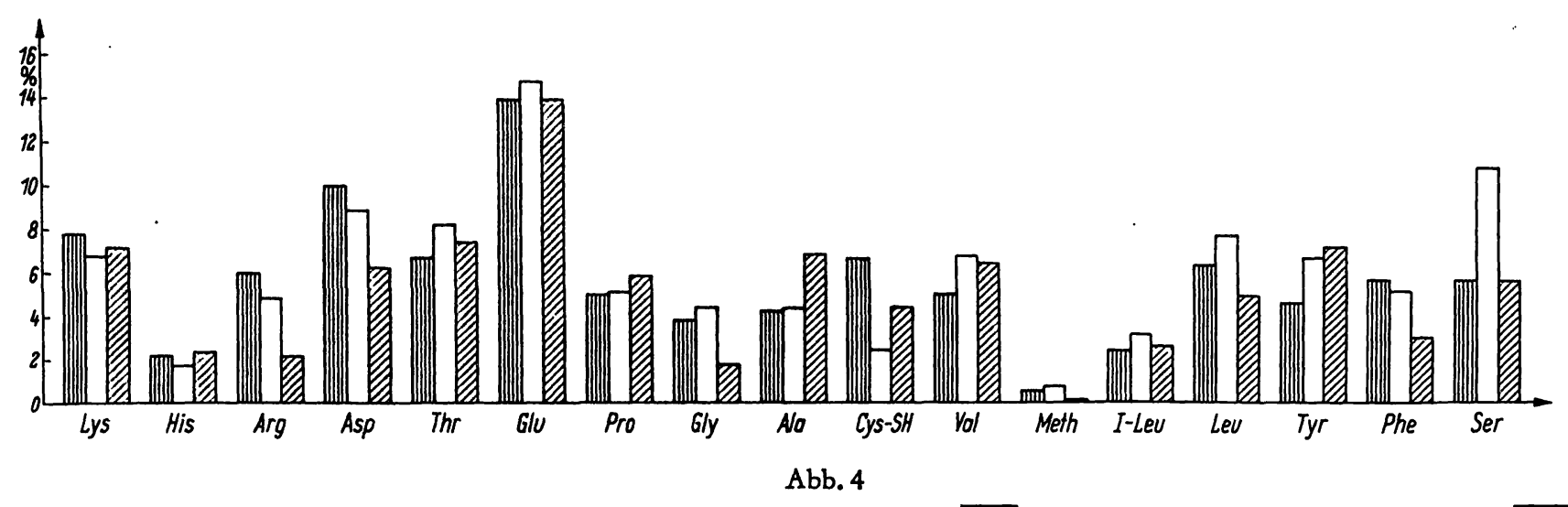

Prozentuale Aminosäureverteilung im Polypeptidanteil des Gesamturoproteins III11, des Bence Jones'schen Eiweißkörpers und des niedermolekularen Glykoproteids WIIIIA

tauscher bestimmt. Die Ausbeute an einzelnen Zuckern war bei den Säurehydrolysen sehr unterschiedlich und ist aus Tabelle $2 \mathrm{zu}$ ersehen. Glukose und Hexosamine wurden mit Salzsäure am besten abgespalten. Ameisensäure und Trichloressigsäure bewirkten eine gute Ausbeute an Methylpentosen; Schwefelsäure war für Hexosen und Methylpentosen am geeignetsten, obgleich die Kohlenhydratgesamtausbeute etwas niedriger lag. Wie erwartet hydrolysierte die Schwefelsäure nur einen geringen Prozentsatz an Hexosaminen. Neuraminsäure konnte von den verwendeten Säuren nur mit Ameisensäure hydrolysiert werden, ohne daß das Molekül zerstört wurde. Die optimale Ausbeute an Kohlenhydraten nach Hydrolyse mit verschiedenen Säuren zeigt, daß die Werte für Hexosamine, Neuraminsäure und Glukose höher liegen, als nach den Untersuchungen mit der eingewogenen Substanz zu erwarten war. $\mathrm{Da}$ nach Säurehydrolysen die chromatographische Trennung der Zucker durch Spuren von Säure, die sich nicht mehr entfernen ließen, gestört war, verwendeten wir noch die sehr schonende Methode einer stufenweisen Hydro- lyse der Kohlenhydrat-Komponenten mit Ionenaustauscher. Durch Änderung des $\mathrm{pH}$ und der Temperatur konnte mit saurem Ionenaustauscher IR 120 50-100 Mesh das Glykoproteid in mehreren Versuchsansätzen hydrolysiert werden. Die in den einzelnen Hydrolysestufen abgespaltenen Komponenten konnten durch Dialyse wiedergewonnen werden. Diese Hydrolysebedingungen erlauben einen Rückschlu $\beta$ auf die Stabilität der Kohlenhydratbindungen im Glykoproteid. Wir fanden mit dieser Methode einen Gesamtkohlenhydratgehalt von $38,1 \%$, der aus $16,6 \%$ Hexosen, $4,5 \%$ Methylpentosen, 10,2\% Hexosamin und 6,8\% Neuraminsäure besteht. Neuraminsäure konnte schon bei Zimmertemperatur und $\mathrm{pH}=5$ teilweise abgespalten werden. Die Gesamtausbeute der Kohlenhydrate liegt etwas höher als bei den Säurehydrolysen. Die chromatographische Trennung der dialysierten Hydrolysate ergab Galaktose, Glukose, Mannose, Fucose, Rhamnose, Glukosamin, Galaktosamin und Neuraminsäure. Paralleluntersuchungen mit der Dünnschichtchromatographie auf MN-Cellulose erlaubten bei sehr guter Trennzeit in

Tab. 2

Vergleich der Kohlenhydratuntersuchungen, ausgeführt mit Glykoproteid direkt mit den Zuckerreagenzien nach Säure- und Ionenaustauscher-Hydrolyse

$\mathrm{N}=$ Gesamtstickstoff (KJELDAHI); $\quad \dot{\mathrm{n}}=$ Anthron-Reaktion; Or=Orcin-Reaktion; $\quad \mathrm{Glu}=$ Glukose, fermentativ bestimmt; HA = Hexosamine nach Elson-MorgaN; NS = Neuraminsäure nach SvenNERHOLM; Ges.KH = Gesamtkohlenhydrate; Ges.\% = Gesamt-Prozent

\begin{tabular}{|c|c|c|c|c|c|c|c|c|c|}
\hline Untersuchungsmaterial & $\mathbf{N}$ & An & Or & Glu & $\begin{array}{l}\text { Methyl- } \\
\text { pentosen }\end{array}$ & $\mathrm{HA}$ & NS & Ges.KH & Ges. $\%$ \\
\hline Glykoproteid $\mathrm{Kö}_{\mathbf{A}_{\mathbf{s}}}$ Substanz & 8,9 & 19 & 24,2 & 0,6 & 3,4 & 7,5 & 1,3 & 37,0 & 91,4 \\
\hline $\begin{array}{l}\text { Glykoproteid hydrol. } 4 \text { Stdn. } \\
4 n \mathrm{HCl} 100^{\circ}\end{array}$ & & 13 & 16,1 & 1,3 & 2,1 & 11,0 & 0,2 & 27,3 & 84,0 \\
\hline $\begin{array}{l}\text { Glykoproteid hydrol. } 4 \text { Stdn. } \\
\text { 80proz. HCOOH } 100^{\circ}\end{array}$ & & 14 & 15,8 & 1,3 & 2,5 & 3,7 & 4,0 & 23,5 & 80,0 \\
\hline $\begin{array}{l}\text { Glykoproteid hydrol. } 4 \text { Stdn. } \\
\text { 50proz. } \mathrm{CCl}_{3} \mathrm{COOH} 100^{\circ}\end{array}$ & & 19 & 23,0 & 1,3 & 3,6 & 8,5 & 0,7 & 32,5 & 88,0 \\
\hline $\begin{array}{l}\text { Glykoproteid hydrol. } 4 \mathrm{Stdn} . \\
\mathrm{H}_{2} \mathrm{SO}_{4} 100^{\circ}\end{array}$ & & 14 & 10,0 & 0,1 & 3,0 & 0,9 & 0,5 & 15,4 & 72,0 \\
\hline $\begin{array}{l}\text { Optimale Ausbeute nach } \\
\text { Säurehydrolyse }\end{array}$ & & 19 & 24,2 & 1,3 & 3,6 & 11,0 & 4,0 & 39,2 & 96,0 \\
\hline $\begin{array}{l}\text { Ausbeuten nach Ionenaus- } \\
\text { tauscher-Hydrolysen mit } \\
\text { Amberlite } \mathrm{pH}=5 \text { und } \mathrm{pH}=1\end{array}$ & & 23,6 & 23,6 & 4,5 & 4,1 & 11,2 & 3,0 & 40,3 & 97,3 \\
\hline
\end{tabular}


kleinen Auftragsmengen häufige, schnell orientierende Kontrolluntersuchungen.

Die partielle Ionenaustauscher-Hydrolyse zeigte, daß etwa $2 \%$ Hexosen, $1 \%$ Methylpentosen, $2 \%$ Neuraminsäure bei $20^{\circ} \mathrm{pH}=5$ nach $3 \mathrm{Stdn}$. abgespalten wurden und durch Dialyse zu isolieren waren. $13 \%$ Hexosen, 2,5\% Pentosen und 2,5\% Neuraminsäure wurden erst nach 2-stdg. Ionenaustauscher-Hydrolyse $\mathrm{pH}=5,100^{\circ}$ erhalten. Die restlichen Hexosen und Methylpentosen wurden nach 3-stdg. Hydrolyse $\mathrm{pH}=1,100^{\circ}$ freigesetzt, wobei der Prozentsatz der Glukose am höchsten lag. Die Hexosamine hafteten an dem Austauscherkorn und wurden mit $0,2 n \mathrm{HCl}$ eluiert. Die Ausbeute betrug 10,2\%. Die restliche Neuraminsäure befand sich nach Hydrolyse $\mathrm{pH}=5,100^{\circ}$ noch im Dialyserückstand, bei Hydrolyse $\mathrm{pH}=1,100^{\circ}$ wurde sie zerstört. - Zur quantitativen Darstellung der einzelnen Zuckerkomponenten wurden die Dialysate und das $0,2 n \mathrm{HCl}$-Eluat nach AustauscherHydrolyse auf einem $25 \mathrm{~cm}$ breiten Chromatogrammbogen mit einer Auftragsmenge von $25 \mathrm{mg}$ aufgetragen und chromatographiert (Abb. 5). Nach Identifizierung

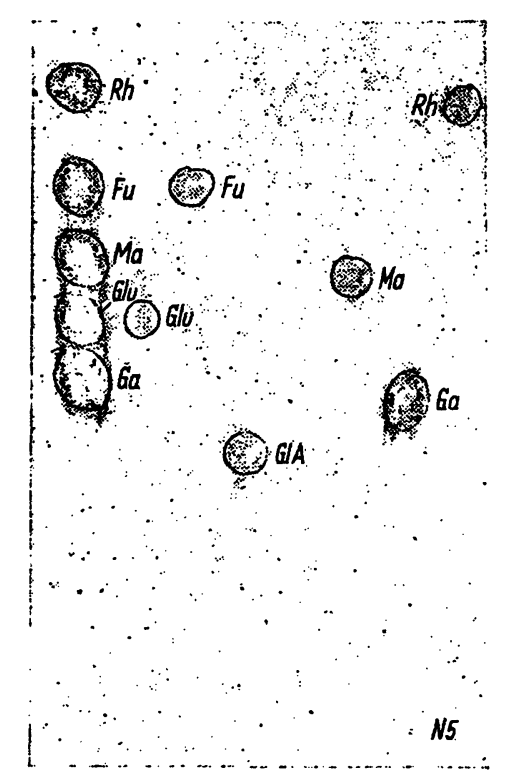

Abb. 5

Chromatogramm der papierchromatographisch getrennten und eluierten Zucker des Glykoproteids nach Ionenaustauscher-Hydrolyse mit Amberlite IR 120, 50-100 Mesh, $\mathrm{pH}=5$ und $\mathrm{pH}=1$, $100^{\circ}, 3$ Stdn.; Lösungsmittel Butanol:Pyridin:Wasser $=1: 3: 5$, 18 Stdn., danach Trocknung, erneute Chromatographie in demselben Lösungsmittel 12 Stdn.

$$
\begin{aligned}
\mathrm{Ga} & =\text { Galaktose } & \mathrm{Rh} & =\text { Rhamnose } \\
\mathrm{Glu} & =\text { Glukose } & \mathrm{NS} & =\text { Neuraminsäure } \\
\mathrm{Ma} & =\text { Mannose } & \mathrm{GIA} & =\text { Glukosamin } \\
\mathrm{Fu} & =\text { Fucose } & &
\end{aligned}
$$

und Elution der einzelnen Zuckerzonen wurde in den Eluaten der Galaktose, Glukose, Maninose, Rhamnose und Fucose mit der Orcin- und Anthron-Methode die Kohlenhydrat-Konzentration bestimmt. Die Extinktionswerte wurden auf den jeweiligen Zuckerstandard bezogen. Die Fucose- und Rhamnose-Konzentrationen wurden außerdem nach Dische und SHEtrues (13) ermittelt, die Glukose wurde mit der Glukoxydase (19) und Hexokinase-Glukose-6-Phosphat-Dehydrogenase (20) fermentativ bestimmt. Glukosamin und Galaktosamin wurden mit der Erson-Morgan-Reaktion (15) ermittelt. Außerdem wurde das Verhältnis der Aminozucker nach Entwicklung des Chromatogrammes mit alk. Silbernitrat photometrisch dargestellt und planimetrisch ausgewertet (17). Neben der quantitativen Aminozucker-Bestimmung und chromatographischen Identifizierung des Glukosamins und Galaktosamins wurden die Hexosamine durch Ninhydrin-Abbau zu den entsprechenden Pentosen Arabinose (Glukosamin) und Lyxose (Galaktosamin) abgebaut und identifiziert (18). Das Vorliegen von Mannosamin, welches ebenfalls durch Ninhydrin zu Arabinose umgesetzt wird, konnte chromatographisch ausgeschlossen werden. Die Neuraminsäure konnte bei Anwendung der Resorcin-Methode nach SVENNERHOLM (14) aus der eingewogenen Glykoproteid-Substanz nur mit $1,2 \%$ erfaßt werden. Nach Verlängerung der Versuchsdauer von $15 \mathrm{Min}$. auf 60 Min. lag die Ausbeute bei $2 \%$. Nach vorausgegangener Hydrolyse mit Ameisensäure war eine Ausbeute von $4 \% \mathrm{zu}$ erzielen. Im Dialysat nach IonenaustauscherHydrolyse bei $\mathrm{pH}=5,20^{\circ}$ und $100^{\circ}$ fanden wir $4 \%$. Der Rest der Neuraminsäure war in dem DialysatRückstand mit der Resorcin-Methode nachweisbar und dürfte noch nicht aus dem Molekülverband freigesetzt worden sein, da sie nicht dialysierte. Nach Ionenaustauscher-Hydrolyse $\mathrm{pH}=1,100^{\circ}$ konnten wir zusammen mit den Aminozuckern praktisch alle Aminosäuren chromatographisch nachweisen, die wir auch nach der Hydrolyse des Glykoproteids mit $4 n \mathrm{HCl}$ 4 Stdn., $100^{\circ}$ erhalten hatten. Hieraus ist zu erkennen, $\mathrm{da} B$ trotz schonender Hydrolyse infolge großer Oberflächenwirkung eine weitgehende Spaltung des Glykoproteids stattgefunden hatte, die annehmen läßt, daß sämtliche Kohlenhydrat-Komponenten abgespalten worden-waren. Die gefundenen 38,1\% der Gesamtkohlenhydrate haben folgende prozentuale Verteilung im Glykoproteid: Ga:Ma:Glu:Fu:Rh:GlA:GaA:NS = $8,1: 4,5: 4,0: 3,2: 1,3: 8,4: 1,8: 6,8$, mit einer molaren Verteilung von 10:5:5:4:2:8:2:5. Das Verhältnis Galaktose:Mannose beträgt 2 (Tab. 3).

\section{Elektrophoretische Untersuchungen}

Elektrophoretische Untersuchungen des Glykoproteids zeigten bei $\mathrm{pH}=7-8,5$ auf Papier, in Stärke und Agar-Gel eine homogene Bande, die mit der Geschwindigkeit der $\alpha_{1}$-Globuline wanderte. Sie war mit Ninhydrin, PAS, Anilinphthalat, alk. Silbernitrat und Amidoschwarz darzustellen. Die Anfärbung mit Amidoschwarz war sehr schwach. Neben dem GlykoproteidCharakter ist daraus zu erkennen, da $\hat{B}$ reduzierende OH-Gruppen endständig sein müssen.

\section{Infrarotspektrum}

Das Infrarotspektrum entsprach dem bereits chemisch, chromatographisch und elektrophoretisch nachgewiesenen Glykoproteidcharakter. Der Kurvenverlauf ist 
Tab. 3

Prozentuale Verteilung der Kohlenhydrate bei Glykoproteiden und Mucoiden des Serums und Urins

\begin{tabular}{|c|c|c|c|c|c|c|c|c|c|c|}
\hline Material & Ga & $\mathrm{Ma}$ & $\mathrm{Ga} / \mathrm{Ma}$ & Glu & $\mathrm{Fu}$ & $\mathrm{Rh}$ & Rib & Hex & NS & Ges.KH \\
\hline$\alpha_{1}$-Serum Mucoid ${ }^{1}$ ) & 9,8 & 4,9 & 2 & - & 0,7 & - & - & 13,9 & 12,1 & 41,4 \\
\hline Haptoglob. $\left.1-1^{1}\right)$ & 5,2 & 2,6 & 2 & - & 0,2 & - & - & 5,3 & 5,3 & 18,6 \\
\hline Haptoglob. $\left.2-1^{1}\right)$ & 4,2 & 2,1 & 2 & - & 0,18 & - & - & 5,9 & 3,1 & 15,5 \\
\hline Haptoglob. $\left.2-2^{1}\right)$ & 3,6 & 1,8 & 2 & - & 0,18 & - & - & 5,5 & 3,4 & 14,5 \\
\hline Transferrin ${ }^{1}$ ) & 1,6 & 0,8 & 2 & - & 0,07 & - & - & 2,0 & 1,4 & 5,9 \\
\hline Coeruloplasmin ${ }^{1}$ ) & 1,5 & 1,5 & 1 & - & 0,18 & - & - & 2,4 & 2,2 & 7,8 \\
\hline$\alpha_{2}$-Makroglobulin ${ }^{1}$ ) & 1,8 & 1,8 & 1 & - & 0,12 & - & - & 2,9 & 1,8 & 8,4 \\
\hline$\beta_{2}$ A-Globulin $\left.{ }^{1}\right)$ & 1,6 & 1,6 & 1 & - & 0,22 & - & - & 1,8 & 1,8 & 7,0 \\
\hline$\gamma$-Makroglobulin ${ }^{1}$ ) & 1,5 & 3,0 & 0,5 & - & 0,70 & - & - & 4,4 & 1,3 & 10,9 \\
\hline normales Harnmucoid'2) & 5,43 & 4,37 & 1,3 & 2,99 & 1,3 & 0,52 & 0,62 & 8,4 & 2,0 & 25,6 \\
\hline $\begin{array}{l}\text { niedermolekulares Glykoproteid } \\
\text { aus Plasmocytom-Urin }{ }^{3} \text { ) }\end{array}$ & 8,1 & 4,5 & 1,8 & 4,0 & 3,2 & 1,3 & - & 8,4 & 6,8 & 38,1 \\
\hline
\end{tabular}

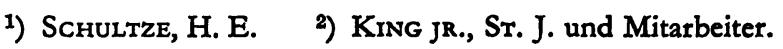

3) Eigene Untersuchungen.

dem Infrarotspektrum des normalen Harnmucoides ähnlich (Abb. 6), obgleich die Aminosäure-Zusammensetzung und die Verteilung der Gesamtkohlenhydrate deutliche Differenzen erkennen lassen (Tab. 4).

Die prozentuale Zusammensetzung des Glykoproteids und die molare Verteilung der Aminosäuren und Kohlenhydrate erlauben eine Berechnung des Molekulargewichtes, das in guter Ubereinstimmung mit dem durch Sedimentations- und Diffusionsläufen in der Ultrazentrifuge gefundenen Molekulargewicht steht. Auf Grund der molaren Verteilung (Tab. 4) sind in dem Glykoproteid 775 C-, 1267 H-, 392 O-, $156 \mathrm{~N}$ und $6 \mathrm{~S}$-Atome anzunehmen. Aus den Ergebnissen mehrfach wiederholter Elementaranalysen, nämlich $\mathrm{C}=47,0 \% ; \mathrm{H}=6,75 \% ; \mathrm{N}=10,8 \% ; \mathrm{S}=1,0 \%$ und dem mit der Ultrazentrifuge bestimmten Molekulargewicht von 19900 konnten wir für das Glykoproteid $779 \mathrm{C}-, 1343 \mathrm{H}-, 428 \mathrm{O}-, 153 \mathrm{~N}-$ und $6 \mathrm{~S}$-Atome berechnen. Die gute Ubereinstimmung in der $\mathrm{Zahl}$ der C-, N- und S-Atome berechtigt zu der Annahme, daß wir alle wesentlichen Aminosäure- und Kohlenhydratkomponenten des Protein-Symplexes mit den durch-
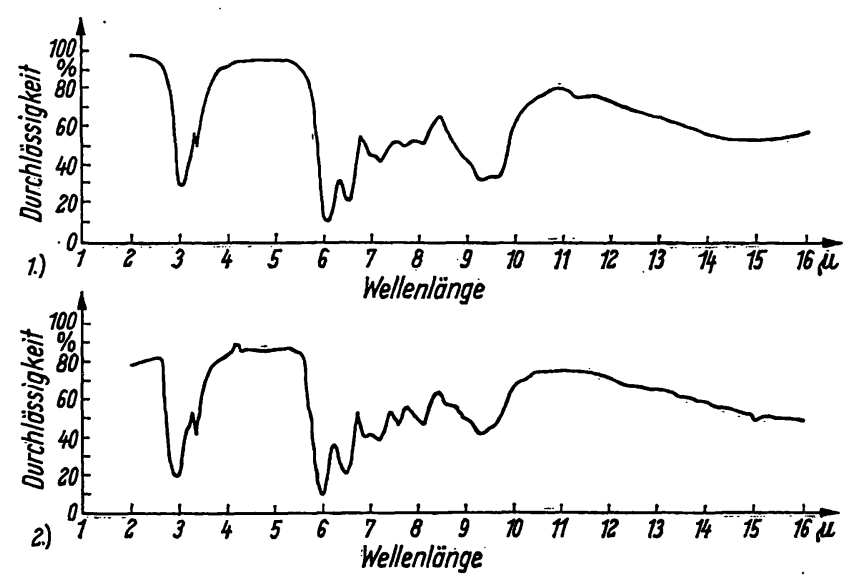

Abb. 6

Infrarotspektrum des Glykoproteids aus Plasmocytom-Urin (1) im Vergleich zu dem Infrarotspektrum des normalen Harnmucoids (2) (KnNG JR., ST. J. und Mitarbeiter). Infrarotspektrograph Perkin Elmer; Kaliumbromid-Preßling
Tab. 4

Prozentuale und molare Verteilung der Aminosäuren und Kohlenhydrate im niedermolekularen Glykoproteid des PlasmocytomUrins und im normalem Harnmucoid ${ }^{\mathrm{I}}$ ) (KING JR., ST. J. u. Mitarb.)

\begin{tabular}{|c|c|c|c|c|}
\hline & $\begin{array}{c}\text { Prozentuale } \\
\text { Verteilung } \\
\text { der AS und } \\
\mathrm{KH} \text { im } \\
\text { Glyko- } \\
\text { proteid }\end{array}$ & $\begin{array}{l}\text { Molare } \\
\text { Verteilung } \\
\text { der AS und } \\
\text { KH im } \\
\text { Glyko- } \\
\text { proteid }\end{array}$ & $\begin{array}{l}\text { Prozentuale } \\
\text { Verteilung } \\
\text { der AS und } \\
\text { KH im nor- } \\
\text { malen Harn- } \\
\text { mucoid }\end{array}$ & $\begin{array}{c}\text { Molare } \\
\text { Verteilung } \\
\text { der KH im } \\
\text { normalen } \\
\text { Harn- } \\
\text { mucoid }\end{array}$ \\
\hline Lys & 4,6 & 7 & 2,508 & \\
\hline $\mathrm{His}$ & 1,5 & 2 & 1,932 & \\
\hline Arg & 1,4 & 2 & 3,948 & \\
\hline Asp & 4,1 & 7 & 6,582 & \\
\hline $\operatorname{Tr}$ & 4,9 & 10 & 4,132 & \\
\hline Ser & 3,9 & 9 & 3,792 & \\
\hline Glu & 9,1 & 14 & 6,161 & \\
\hline Pro & 3,9 & 8 & 2,526 & \\
\hline Gly & 1,2 & 4 & 2,762 & \\
\hline $\mathrm{Ala}$ & 4,4 & 12 & 3,041 & \\
\hline Cys-SH & 2,85 & 6 & 3,326 & \\
\hline Val & 4,35 & 9 & 3,730 & \\
\hline Meth & - & - & 1,524 & \\
\hline Ileu & 1,7 & 3 & 1,972 & \\
\hline Leu & 3,3 & 6 & 4,966 & \\
\hline Tyr & 4,8 & 6 & 3,159 & \\
\hline Phe & 2,0 & 3 & 2,675 & \\
\hline $\mathrm{NH}_{2}$ & 1,8 & (21) & 1,609 & \\
\hline
\end{tabular}

\begin{tabular}{lcrcc}
\hline $\begin{array}{l}\text { Summe der } \\
\text { AS in \% }\end{array}$ & $59,8 \%$ & 108 & Ges. $\% 58,737$ & \\
\hline Gal & 8,1 & 10 & 5,43 & 8 \\
Man & 4,5 & 5 & 4,37 & 6 \\
Glu & 4,0 & 5 & 2,99 & 4 \\
Fu & 3,2 & 4 & 1,30 & 3 \\
Rham & 1,3 & 2 & 0,52 & 1 \\
Rib & - & - & 0,62 & 1 \\
NA Glc-NH & 8,4 & 8 & 8,40 & - \\
NA Gal-NH & 1,8 & 2 & 0,30 & - \\
Sialins. & 6,8 & 5 & 2,00 & - \\
\hline
\end{tabular}

Summe der

Ges. $\mathrm{KH}$ in \% $\quad 38,1 \% \quad 41 \quad 25,93$

23

1) Berechnung der prozentualen und molaren Verteilung im Molekụil unter Abzug von $146 \mathrm{H}_{2} \mathrm{O}$ bei insgesamt $142 \mathrm{AS}$ und $\mathrm{KH}$. 
Tab. 5

Prozentuale Verteilung des Gesamtstickstoffes und der Kohlenhydrate bei Glykoproteiden und Mucoiden des Serums und Urins $\mathrm{N}=$ Gesamtstickstoff, $\mathrm{E}=$ Eiweiß, berechnet aus Gesamtstickstoff, $\mathrm{B}=$ Biuret-Wert, Hex $=$ Hexosen, $\mathrm{Ga}=\mathrm{Galaktose}, \mathrm{Ma}=\mathrm{Mannose}$, $\mathrm{Glu}=$ Glukose, $\mathrm{Fu}=$ Fucose, $\mathrm{Rh}=$ Rhamnose, $\mathrm{HA}=$ Hexosamine, $\mathrm{GIA}=$ Glukosamin, $\mathrm{GaA} \doteq$ Galaktosamin, $\mathrm{NS}=\mathrm{Neuramin}-$ säure, Ges. $\mathrm{KH}=$ Gesamtkohlenhydrate, $\mathrm{MG}=$ Molekulargewicht, $\mathrm{iP}=$ isoelektrischer Punkt

\begin{tabular}{|c|c|c|c|c|c|c|c|c|c|c|c|c|c|c|c|c|c|c|}
\hline Glycoproteide & Autoren & $\mathrm{N}$ & $\mathrm{E}$ & B & Hex & $\mathrm{Ga}$ & $\mathrm{Ma} \mathrm{G}$ & $\mathrm{Ga} / \mathrm{Ma}$ & Glu & $\mathrm{Fu}$ & $\mathbf{R h}$ & $\mathrm{HA}$ & GIAGaA & NS & $\begin{array}{l}\text { Ges.- } \\
\mathrm{KH}\end{array}$ & MG & \multicolumn{2}{|c|}{$\begin{array}{l}\text { iP } \mathrm{mg} / 100 \\
\mathrm{mlSerum}\end{array}$} \\
\hline$\alpha_{1}$-Globulin & 1) & & & & 7,5 & & & & & 0,55 & & 6,3 & & 4,1 & 18,5 & & & \\
\hline$\alpha_{2}$-Globulin & 1) & & & & 5,9 & & & & & 0,4 & & 4,2 & & 3,0 & 13,5 & & & \\
\hline$\beta$-Globulin & 1) & & & & 2,7 & & & & & 0,2 & & 1,9 & & 1,5 & 6,3 & & & \\
\hline$\gamma$-Globulin & 1) & & & & 1,9 & & & & & 0,3 & & 1,5 & & 1,2 & 4,9 & & & \\
\hline Serummucoid & 1) & 10,9 & 68 & & 14,3 & & & & & 1,0 & & 10,0 & & 9,0 & 34,3 & & & \\
\hline Orosomucoid & 1) & 10,1 & & 63 & 15,0 & & & 2 & & 1,0 & & 12,0 & & 12,0 & 41,0 & 410001 & $1,8-2,7$ & 775 \\
\hline Orosomucoid & Easton J.A. & 9,4 & & 50 & 16,7 & & & & & & & & & 10,7 & & & & \\
\hline Orosomucoid & Schmidt K. & 10,7 & & 66 & 17,2 & & & & & & & & & 10,6 & & & & \\
\hline $\begin{array}{c}\alpha_{1} \text { Glycoprotein } \\
3,5 \mathrm{~S}\end{array}$ & $\begin{array}{l}\text { 1) Schultze } \\
\text { H. E. }\end{array}$ & 13,3 & & 84 & 6,8 & & & & & & & 3,6 & & 3,3 & 13,7 & 54000 & & 30 \\
\hline$a_{2}$ Small Globulin & $n \quad 1)$ & 12,6 & & 80 & 5,0 & & & & & & & 3,5 & & 7,0 & 15,5 & $S_{20}=2,6$ & 3,85 & \\
\hline$a_{2}$ Makroglobulin & $\begin{array}{l}\text { 1) Schultze } \\
\text { H. E. }\end{array}$ & 14,8 & & 92 & 3,6 & & & 1 & & 0,12 & & 2,3 & & 1,8 & 7,8 & $\begin{array}{l}S_{20}=19 \\
850000\end{array}$ & & 240 \\
\hline$\alpha_{2}$ Makroglobulin & (1) Brown & & & 98 & 5,3 & & & & & . & & 3,8 & & & & $S_{20}=16,3$ & & 240 \\
\hline$\alpha_{2}$ Makroglobulin & $\begin{array}{l}\left.{ }^{1}\right) \text { Müller- } \\
\text { Eberhard H.J }\end{array}$ & 14,2 & & & 4,8 & & & & & & & 2,7 & & 2,3 & 9,8 & $S_{20}=19$ & & \\
\hline Transferrin & 1) & 15,4 & & 95 & 2,4 & & & 2 & & 0,07 & & 1,6 & & 1,4 & 5,5 & 88000 & 5,9 & 400 \\
\hline Coeruloplasmin & 1) & 13,8 & & 95 & 3,0 & & & 2 & & 0,18 & & 1,9 & & 2,0 & 7,1 & 151000 & 4,4 & 30 \\
\hline Haptoglobulin & 1) & 12,9 & & 83 & 11,3 & & & 1 & & 0,18 & & 5,7 & & 5,5 & 22,7 & $\begin{array}{r}85000 \\
170000\end{array}$ & 4,1 & 100 \\
\hline$\beta_{2} \mathrm{~A}-$ Globulin & 1) & 16,2 & & & 4,9 & & & & & & & 3,7 & & & & $S_{20}=7$ & & \\
\hline$\gamma$-Globulin $7_{s}$ & 1) & 15,6 & & 97 & 1,2 & & & 0,5 & & 0,29 & & 1,4 & & 0,22 & 3,1 & 157000 & & 1480 \\
\hline$\gamma$-Globulin $19 s$ & 1) & 14,6 & & & 5,2 & & & & & 0,62 & & 2,9 & & 1,7 & 10,4 & $S_{20}=19$ & & \\
\hline Makroglobulin & Metais & & & & 3,5 & & & & & 0,52 & & 1,6 & & 0,6 & 6,2 & & & \\
\hline Makroglobulin & $\begin{array}{l}\text { Müller-Eber- } \\
\text { hard H. J. }\end{array}$ & & & & 4,85 & & & & & 0,62 & & 2,66 & & 1,71 & 9,84 & & & \\
\hline Makroglobulin & Weicker, $\mathrm{H}$. & 14,0 & 88 & 80 & 4,5 & & & & & 0,61 & & 2,2 & & $.1,4$ & 8,6 & & & \\
\hline$\beta_{2} \mathrm{M}$ & 1) & & & & 4,85 & & & & & 0,62 & & 2,7 & & 1,71 & 9,9 & & & \\
\hline Myelom-Protein & 1) & & & & $08-04$ & & & & & & & $08-3,1$ & & & & & & \\
\hline Cryoglobulin & Weicker, $\mathrm{H}$. & 11,0 & & 75 & 2,3 & & & & & & & 3,0 & & 0,8 & 6,1 & & & \\
\hline Urin-Mucoide & $\begin{array}{l}\text { Tamm } \\
\text { Horsfall }\end{array}$ & 11,0 & & & $\begin{array}{l}6,8- \\
9,0\end{array}$ & & & & & $\begin{array}{l}0,7- \\
1,1\end{array}$ & & 8,4 & & $\begin{array}{l}7,3 \\
9,1\end{array}$ & & $7,10^{6}$ & & Urin \\
\hline Urin-Mucoide & King, jr. St.J & $.11,0$ & & & & 5,4 & 4,4 & 1,2 & 2,99 & 1,30 & $\begin{array}{l}0,52 \\
0,62\end{array}$ & 8,4 & & 2,0 & 25,6 & & & \\
\hline $\begin{array}{l}\text { Urin-Glykopro- } \\
\text { teid normal }\end{array}$ & Tunis, $\mathrm{M}$. & & & 70 & 7,5 & & & & & & & 6,3 & & 6,3 & 20,1 & & & \\
\hline Leukämie Fr. I & Tunis, $M$. & & & 86 & 4,6 & & & & & & & 4,0 & & 5,0 & 13,6 & & & \\
\hline Leukämie Fr. II & Tunis, $\mathrm{M}$. & & & 71 & 7,2 & & & & & & & 6,9 & & 6,3 & 26,5 & & & \\
\hline $\begin{array}{l}\text { Myeloische } \\
\text { Leukämie Fr. I }\end{array}$ & Tunis, $\mathbf{M}$. & & & $\begin{array}{l}68 \\
89\end{array}$ & 8,2 & & & & & & & $\begin{array}{l}7,8 \\
9,4\end{array}$ & & $\begin{array}{l}8,0 \\
9,1\end{array}$ & $\begin{array}{l}24,0 \\
26,7\end{array}$ & & & \\
\hline $\begin{array}{l}\text { Myeloische } \\
\text { Leukämie Fr. II }\end{array}$ & Tunis, $M$. & & & $\begin{array}{l}74 \\
85\end{array}$ & $\begin{array}{l}8,5 \\
9,8\end{array}$ & & & & & & & $\begin{array}{l}6,8 \\
9,1\end{array}$ & & $\begin{array}{l}7,5 \\
8,2\end{array}$ & $\begin{array}{l}22,8 \\
27,1\end{array}$ & & & \\
\hline $\begin{array}{l}\text { Urin-Glykopep- } \\
\text { tide Frakt. I }\end{array}$ & $\begin{array}{l}\text { Hakomori, } \\
\text { S. }\end{array}$ & & & + & 13,5 & + & & & + & 5,6 & & $\varnothing$ & & $\varnothing$ & 19,1 & & & \\
\hline $\begin{array}{l}\text { Urin-Glykopep- } \\
\text { tide Frakt. II }\end{array}$ & $\begin{array}{l}\text { Hakomori, } \\
\text { S. }\end{array}$ & & & + & 5,6 & & & & + & 0,2 & & $\varnothing$ & & $\varnothing$ & 5,8 & & & \\
\hline $\begin{array}{l}\text { Urin-Glykopep- } \\
\text { tide Frakt. III }\end{array}$ & $\begin{array}{l}\text { Hakomori, } \\
\text { S. }\end{array}$ & & & + & 7,5 & & + & & + & 2,5 & & 3,5 & + & $\varnothing$ & 13,5 & & & \\
\hline $\begin{array}{l}\text { Urin-Glykopro- } \\
\text { teid Plasmocytom }\end{array}$ & $\begin{array}{l}\text { Weicker, } \\
\text { H. }\end{array}$ & 14,3 & 90 & 87 & 3,3 & & & & ${ }^{\circ}$ & & & 1,0 & & 0,8 & 5,1 & 53000 & & 1070 \\
\hline $\begin{array}{l}\text { Ges. Uroproteid } \\
\text { BJ-Hitzefällung }\end{array}$ & Weicker, $\mathrm{H}$. & 13,7 & 86 & 85 & $\dot{1,3}$ & & & & & & & 0,5 & & 0,3 & 2,1 & 35000 & & 720 \\
\hline $\begin{array}{l}\text { BJ-Ammonium- } \\
\text { sulfatfällung }\end{array}$ & Weicker, $\mathrm{H}$. & 14,6 & 91,2 & 90 & 1,5 & & & & & & & 2,0 & & 0,5 & 4,0 & 35000 & & 700 \\
\hline $\begin{array}{l}\text { Glykoproteid } \\
\text { niedermolekular }\end{array}$ & Weicker, H. & 8,9 & 66 & 57 & 16,6 & 8,1 & 4,5 & 1,8 & 4,0 & 3,2 & 1,3 & 10,2 & $8,4 \quad 1,8$ & 6,8 & 38,1 & $\begin{array}{c}19000 \\
S_{20}=1,43\end{array}$ & $\begin{array}{r}3,3 \\
3,6\end{array}$ & 50 \\
\hline
\end{tabular}

1) Zitiert nach WINZLER, R. J. 
geführten Untersuchungen erfaßt haben. Das aus den 108 Aminosäuren und 41 Kohlenhydraten errechnete Molekulargewicht von 19215, verglichen mit dem in der analytischen Ultrazentrifuge ermittelten Molekulargewicht von 19900, stützt ebenfalls diese Annahme.

\section{Diskussion}

Das relativ niedermolekulare Glykoproteid, isoliert aus Plasmocytom-Urin, hat im wesentlichen die Eigenschaften, die für Perchlorsäure-lösliche Glykoproteide charakteristisch sind (23). Abweichungen zeigen sich jedoch sowohl in der Aminosäure- und Kohlenhydrat-Zusammensetzung als auch in den physiko-chemischen Untersuchungsergebnissen, die diesem Glykoproteid eine Sonderstellung unter den Perchlorsäure-löslichen Protein-Symplexen einräumen und seine Atypie kennzeichnen. Es ist in der horizontalen Papierelektrophorese und in der Stärke-Gel-Elektrophorese bei $\mathrm{pH}=7-8,5$ einheitlich. Die elektrophoretische Wanderung entspricht dem $\alpha_{1}$-Globulin. Der isoelektrische Punkt liegt zwischen 3,3-3,6. Die Immunoelektrophorese zeigt eine partielle Antigen-Gemeinschaft der im Bereich der $\alpha_{1}$-Globuline lokalisierten Präzipitationslinien gegen Antihumanserum. Bei der Sedimentationsanalyse in der Ultrazentrifuge ist das Glykoproteid homogen, die Sedimentationskonstante $\left(\mathrm{S}^{\circ}{ }_{20}\right)$ beträgt 1,43. Das Molekulargewicht ist bei kombinierter Sedimentations- und Diffusionsmessung 19900. Es enthält die 16 verschiedenen Aminosäuren, die auch im Bence Jones'schen Protein vorkommen $(21,22,24)$ und ist methioninfrei. Es unterschreidet sich von dem Gesamturoprotein und dem Bence Jones'schen Eiweißkörper durch seine prozentuale Aminosäure-Zusammensetzung und besonders durch seinen bedeutend höheren Gesamtkohlenhydratgehalt. Bei einem Verhältnis Polypeptid: Kohlenhydrat $=1,5: 1$. haben wir 38,1\% Gesamtkohlenhydrate, die aus $16,6 \%$ Hexosen, $4,5 \%$ Methylpentosen, $10,2 \%$ Hexosaminen und $6,8 \%$ Neuraminsäure bestehen. Wir fanden neben $8,1 \%$ Galaktose und $4,5 \% \mathrm{Man}$ nose 4,0\% Glukose, die bei anderen Glykoproteiden oder Mucoiden des Serums bis jetzt noch nicht beschrieben wurde (25-30). Bei den Mucoiden des Urins lag der Glukose-Gehalt niedriger (Tab. 5); (31-37). Neben der chromatographischen Sicherung der Glukose wurde im Hinblick auf die Bedeutung dieses Befundes noch der spezifische Ferment-Nachweis mit Glucoxydase (19) und Hexokinase-Glukose-6-Phosphat-Dehydrogenase (20) durchgeführt, da die Ausbeute zum spezifischen Osazon-Nachweis zu klein war. Der hohe Prozentsatz von Fucose mit 3,2\% wurde bis jetzt bei anderen Serum- und Urin-Mucoiden noch nicht beschrieben $(28,29,30,34)$. Neben dieser Methylpentose liegt, soweit aus der chromatographischen Identifizierung mit alkalischem Silbernitrat und Perjodat=Benzidin zu entnehmen ist, auch noch eine zweite Methylpentose, und zwar Rhamnose, vor (34). Die 10,2\% Hexosamine bestehen aus $8,4 \%$ Glukosamin und 1,8\% Galaktosamin. Von den $6,8 \%$ Neuraminsäure dürțten nach dem Ergebnis der stufenweisen Hydrolyse mit Ionenaustauscher nur
$3-4 \%$ endständig sein. Die Sicherung dieses Ergebnisses müßte jedoch noch durch die Neuraminidase-Abspaltung der endständigen Neuraminsäure endgültig belegt werden. Hexosamine und Neuraminsäure liegen in dem Glykoproteid in der N-Acetylform vor. - Die Gesamtkohlenhydrate haben folgende molare Verteilung :

Galaktose : Mannose : Glukose : Fucose : Rhamnose : Glukosamin : Galaktosamin : Neuraminsäure $=10: 5$ : $5: 4: 2: 8: 2: 5$. Vergleicht man die Daten dieses Glykoproteids mit den Werten von bereits ausführlich untersuchten anderen Glykoproteiden und Mucoiden, wie sie in Tabelle 5 zusammengefaßt sind, dann findet man, daß das hier isolierte Glykoproteid mit seinem Molekulargewicht niedriger liegt als alle anderen bekannten Glykoproteide und Mucoide, die im Serum und Urin beschrieben wurden. Entsprechend dem Hexose-Gehalt, der elektrophoretischen Wanderung, dem isoelektrischen Punkt gleicht es in seiner Zusammensetzung am ehesten : der Orosomucoid-Gruppe $(25,26,29,30,38,39)$. Jedoch erlauben der hohe Fucose-Gehalt, der Nachweis einer zweiten Methylpentose, das Vorkommen von Glukose und die Fällbarkeit in Trichloressigsäure eine eindeutige Differenzierung von diesem sauren Glykoproteid. Auch das Fehlen von Methionin im Polypeptid-Anteil ermöglicht eine Unterscheidung. Die von TAMM und Horsfall jr. isolierten Harnmucoide (36) haben eine ähnliche Kohlenhydrat-Zusammensetzung, jedoch ein weit höheres Molekulargewicht, das bei etwa 1 Million liegt. Außerdem ist der Fucose-Gehalt niedriger und der Neuraminsäure-Anteil höher. Glukose wurde bei diesen Harnmucoiden nicht beschrieben. Die von KING und Mitarbeitern (34) und Tunis und Mitarbeitern (37) analysierten Harnmucoide aus Normalurin und aus dem Urin von Leukämie-Patienten enthielten ebenfalls Glukose und relativ viel Methylpentose. Sie sind jedoch methioninhaltig und unterscheiden sich in ihrer quantitativen Kohlenhydrat-Zusammensetzung und dem Gesamtkohlenhydrat-Gehalt von dem hier beschriebenen Glykoproteid des Plasmocytom-Urins (Tab. 5). Auch die Unlöslichkeit in 10 proz. Trichloressigsäure ist eine Eigenschaft des Glykoproteids, die bei den anderen Harnmucoiden nicht beschrieben wurde.

Diese Untersuchungen geben zwat noch keinen Einblick in die Konstitution des Glykopeptids, doch ist aus der stufenweisen Hydrolyse mit Ionenaustauscher und nachfolgender Dialyse bereits zu erkennen, daß die Neuraminsäure und die Methylpentosen sehr leicht abzuspalten sind. Es ist deshalb naheliegend, eine endständig oder benachbart endständige Stellung dieser Kohlenhydrate anzunehmen. Nur ein Teil der Hexosen ist mit Ionenaustauscher schon bei $\mathrm{pH}=5,100^{\circ} \mathrm{zu}$ hydrolysieren, der Rest wird erst bei $\mathrm{pH}=1,100^{\circ}$ abgespalten. Der größte Anteil der Glukose und die gesamten Hexosamine wurden bei $\mathrm{pH}=1,100^{\circ}$ hydrolysiert. Hierbei liegen die Versuchsbedingungen vor, unter denen auch die Aminosäuren des Glykoproteids hydrolysiert wurden. 
Das aus der molaren Verteilung errechnete Molekulargewicht und die entsprechende Anzahl der C-, N- und $\mathrm{S}$-Atome stehen mit dem gefundenen Molekulargewicht und der Anzahl der C-, N- und S-Atome in guter Ubereinstimmung. Dies berechtigt zu der Annahme, da $B$ wir mit 108 Aminosäuren und 41 Kohlenhydraten alle wesentlichen Komponenten des isolierten Glykoproteids erfaßt haben. Nach den Ergebnissen von NolaN und SMrth $(40,41)$ sowie Rosvear und SMIth (42), die zeigen konnten, daß Glykoproteide durch Papain in Oligoglykopeptide gespalten werden, muß in Erwägung gezogen werden, ob beim Glykoproteid aus Plasmocytomurin nicht ähnliche Verhältnisse vorliegen. - Betrachtet man nun dieses Glykoproteid als Teil des Gesamturoproteins beim Plasmocytom, dann findet man, daß es erst einer Analyse zugängig wird, wenn der Gesamtkomplex durch die zahlreichen Stufen der Aufarbeitung in die einzelnen Komponenten zerlegt ist. Das immunologisch heterogene Gesamturoprotein ist vor der Durchführung dieser Aufarbeitung bei Untersuchungen in der Papier-, Stärke-Gel-Elektrophorese und Ultrazentrifuge ein kohlenhydratarmer Proteinkomplex, der einheitlich erscheint, obgleich er aus dem Bence Jones'schen Protein, mehreren Lipidkomponenten und dem isolierten Glykoproteid besteht. Der hohe Kohlenhydratanteil des relativ niedermolekularen Glyko- proteids dürfte für den Gesamturoprotein-Komplex, besonders für den Ausfall der Bence Jones'schen Kochprobe, eine wesentliche Bedeutung haben. Das Verhältnis des Glykoproteids zu dem Bence Jones'schen Protein ist für die reversible, irreversible oder partiell irreversible Koagulation des Uroproteins bei der Kochprobe entscheidend. Die Ergebnisse der hier durchgeführten Untersuchungen lassen im Vergleich zu den Glykoproteiden des Serums und des Urins bei Gesunden und bei Patienten mit Proteinurie anderer Genese erkennen, daß das Glykoproteid aus Plasmocytomharn sowohl in seiner Aminosäure- und Kohlenhydratzusammensetzung als auch in seinen physiko-chemischen Eigenschaften eine Sonderstellung einnimmt, die für Paraproteinosen spezifisch sein könnte.

Wir danken Herrn Dr. F. KNücher, Herzheilstätte Königsstuhl der Landesversicherungsanstalt Baden, Heidelberg, für die Untersuchungen mit der Stärke-Gel-Elektrophorese, Herrn Dr. TRäXLER und Fräulein I. HöFER, Beckman Instruments GmbH., München, für die Bestimmungen des Molekulargewichtes mit der Ultrazentrifuge, Herrn Dr. H. Orring, Max-Planck-Institut für medizinische Forschung, Heidelberg, für die Aufnahme des Infrarotspektrums, Herrn Dr. F. A. ANDERER, Max-Planck-Institut für Virusforschung, Tübingen, für die quantitativen AminosäureBestimmungen. Fräulein R. VöLKer und Fräulein U. Burg, Medizinische Universitätspoliklinik Heidelberg, danken wir für ihre wertrolle Mithilfe bei allen biochemischen Untersuchungen.

\section{Literatur}

1. WeICKER, H. und K. HuHNStock, Klin. Wschr. 39, 471 (1961). - 2. Weicker, H. und K. Huhnstock, Klin. Wschr. 40, 44 (1962). - 3. Weicker, H. und K. Huhnstock, Dtsch. Arch. klin. Med. 208, 389 (1962). - 4. WerCKER, H. und K. HuHNSTOCK, Nature London 196, 480 (1962). - 5. Clotren, R. und A. Clotten, Hochspannungselektrophorese. Georg Thieme Verlag, Stuttgart (1962). - 6. KNücheL, F., Dtsch. Zschr. gerichtl. Med. 51, 464 (1961). - 7. Scherdegger, J. J., Internat. Arch. Allergy 7, 103 (1955). - 8. Osserman, E. F., J. Immunol., Baltimore 84, 93 (1960). - 9. Ouchterlony, Ö., Ark. Kemi Ser. B 26, 1 (1949). 10. Svedberg, T. und K. O. Pedersen, The ultracentrifuge Clarendon Press, Oxford (1940). - 11. Northrup, J.H. und M.L. Anson, J. Gen. Physiol. 12543 (1929). - 12. Spackman, H. D., W. H. Stein und S. Moore, Analytic. Chem. 30, 1190 (1958). 13. Dische, Z. und L. B. Shetrles, J. biol. Chemistry 175, 595 (1948). - 14. Svennerholm, L., Biochim. biophysica Acta (Amsterdam) 24, 604 (1957). - 15. Gardell, S., Acta chem. scand. 7, 207 (1953). - 16. SChwEIGER, A., J. of Chromatogr. (Amsterdam) 3, 374 (1962). - 17. SchozNemanN, K., G. JescheK und K. Frommhold, Z. analyt. Chem. 181, 338 (1961). - 18. Gardell, S., F. HeYensKJold und A. RochMorlund, Acta chem. scand. 4, 970 (1950). - 19. SüDhor, H. und P. K. RregeL, Klin. Wschr. 38, 138 (1960). - 20. Barthelmai, W. und R. Czok, Klin. Wschr. 40, 585 (1962). - 21. DeNt, C. E. und G. A. Rose, Biochem. J. 44, 610 (1949). - 22. Schreier, K. und H. PlücKTHUN, Klin. W'schr. 30, 677 (1952). - 23. Schultze, H. E., K. Heide und H. Haupt, Clin. chim. Acta (Amsterdam) 7, 854
(1962). - 24. Edelman, G. M. und J. A. Gally, J. Exper. Med. 116, 207 (1962). - 25. Easton, J: A., J. Hardwicke und P. H. Whitehead, J. Clin. Path., London 15, 585 (1962). - 26. KAMIYAMA, S. und K. SCHMID, Biochim. biophysica Acta (Amsterdam) 58, 80 (1962). - 27. Südhof, H. und H. KellNER, Physiologie und klinische Bedeutung kohlenhydrathaltiger Körperstoffe, S. Karger, Basel, S. 25-27 (1957). - 28. SchurtzE, H. E., Bull. Schweiz. Akad. Med. Wiss. 17, 77 (1961). - 29. SchultzE, H. E., R. SCHMIDTBER GER und H. HAUPT, Biochem. Z. 329, 490 (1958). 30. Winzler, R. J., The plasmaproteins, Academic Press, New York und London, Vol. 1 (1960). - 31. Bourrillon, R., P. Cornillor und R. Got, Clin. chim. Acta (Amsterdam) 7, 506 (1962). 32. Bourrillon, R., R. Got und P. Cornillot, Clin. chim. Acta (Amsterdam) 6, 730 (1961). - 33. Bourrillon, R., R. Gor und J. MrchoN, Clin. chim. Acta (Amsterdam) 6, 91 (1961). - 34. KING JR., J. ST., M. L. FirLdEN und W. H. BoyCE, Arch. Biochem. Biophysics 95, 424 (1961). - 35. KING JR., J. ST., M. L. FIELdEN und W. H. Boyce, Clin. chim. Acta (Amsterdam) 7, 316 (1962). - 36. Tamm, I und F.L. Horsfall JR., Proc. Soc. exp. Biol. Med. 74, 108 (1950). - 37. Tunis, M. und H. WeINFELD, Cancer Res. 22, 764 (1962). - 38. ExLAR, E. H. und R. W. Jeanloz, J. biol. Chemistry 237, 622 (1962). - 39. Lundblad, A. und J. Berggard, Biochim. biophysica Acta (Amsterdam) 57, 129 (1962). - 40. Notan, Ch. und E. L. Smitk, J. biol. Chemistry 237, 446 (1962). - 41. Nolan, Ch. und E. L. Smith, J. biol. Chemistry 237, 453 (1962). - 42. Rosevear, J. W. und E. L. Smrth, J. biol. Chemistry 236, 425 (1961). 